\title{
The Impact of Awareness of New Artificial Intelligence Technologies on Policy Governance on Risk
}

\author{
Do-Hyung Yee $^{1} \&$ Yen-Yoo You ${ }^{1}$ \\ ${ }^{1}$ Dept. of Knowledge Service \& Consulting, Hansung University, Seoul, South Korea \\ Correspondence: Do-Hyung Yee, Dept. of Knowledge Service \& Consulting, Hansung University, Seoul, South \\ Korea. Tel: 82-10-2001-1189. E-mail: andy@lon2seo.com
}

Received: April 9, 2020

Accepted: May 9, 2020

Online Published: May 23, 2020

doi:10.5430/rwe.v11n2p152

URL: https://doi.org/10.5430/rwe.v11n2p152

\begin{abstract}
Background/Objectives: This study examined the risks of new AI technologies and their impact on policy governance. Artificial intelligence is bringing about changes in various fields such as politics, economy and culture through information society and technology. In particular, it has a positive effect on solving various problems of existing society and overcoming limitations. But this advancement in artificial intelligence can create the opposite problem as expected. This appears to be a risk. We identify the factors that recognize this risk and investigate the possible impact on government governance.

Methods/Statistical analysis: The questionnaire and data of this journal were analyzed by Korean public portal data, and the analysis data were designated by the Korea Information Technology Agency, AI related company, AI association, Ministry of Science, ICT and Future Planning, IT society, government research institute, Korea Communications Commission, and National Security Agency The questionnaire survey was based on AI experts working in the field.
\end{abstract}

The analysis program uses IBM SPSS Statistics 22 . The analysis methods are descriptive statistical analysis, reliability analysis and exploratory factor analysis.

Findings: This study examined the risks of new AI technologies and their impact on policy governance. The survey was conducted to clarify comments on awareness of new AI-related technologies, awareness of AI risks, and improvements to AI-related policies.

AI risk has become an integral part of regulation and the government's role as a risk manager is important.

Improvements/Applications: Further discussion is needed regarding the commercialization effects of AI technology awareness, benefit items and timing items on policy governance through risk awareness.

Keywords: AI, demage, government policy, AI technololgy benefits, government policy

\section{Introduction}

The development of computer software and the development of hardware are bringing tremendous changes to society, including economy, culture, and politics, through big data analysis.

This is happening at an increasingly fast pace. Technology development has the positive effect of revolutionizing many areas of artificial intelligence, solving existing social problems and creating opportunities.

On the other hand, these artificial intelligence technologies are two-sided, which can cause bigger problems than the ones they solved.

The pessimism around AI says that it has a spectrum that ranges from job loss due to weak AI automation to the end of humanity following the emergence of strong AI.

Depending on the commercialization stage of AI technology, various policy responses need to be prepared. The Effective Altruism Foundation classifies current AI risks into current, mid-term, and long-term and proposes appropriate policy alternatives. (Effective Altruism Foundation, 2015)

Features of AI can increase the unpredictability of risks, transfer risks to social warfare, and spread these risks from online to offline. 
This study examined how the recognition factors for new artificial intelligence technologies affect policy governance based on the perception of risk.

\section{Materials and Methods}

Artificial intelligence, which combines advanced innovations such as big data analysis, smart factories, and the Internet of Things, has various forms, from optimism and simple malfunctions of convenience, efficiency, and new market creation, to medical accidents, military robots, financial events, and unemployment.

The view of artificial intelligence optimism is basically a view of future technology as a new growth engine. The basis for this is the improvement of productivity due to technology development, the creation of new jobs and the improvement of the quality of life (Barrat, 2013).

Governments and corporations must also prepare for intellectually, technologically, politically, ethically, and socially (Paul, 2017).

The possibility that more than 47\% of jobs in the US will disappear within the next 20 years (Frey and Osborne, 2013) and the emergence of robots and artificial intelligence technology are also increasing the possibility of an existential risk that shakes the human foundation itself (Bostrom, 2002). The development of Korea has greatly changed the number and type of jobs, and ahead of human intelligence, threatening current jobs and furthermore, the era of full employment will be impossible. (Hutzler et al., 2003)

Science and technology are both a source of amazing productivity and a source of lethality. (Energy Outlook, 2004)

Most of these claims of optimism are focused on improving the productivity of firms and focusing on evaluating technological developments in terms of efficiency and convenience.

Pessimism to look at artificial intelligence reflects the problems of the current society such as digital divide and inequality, and there are various forms, from the problem of job loss due to the automation of artificial intelligence to the end of mankind due to the emergence of artificial intelligence.

As the 4th Industrial Revolution, such as Big Data and Smart Factory, has gained great attention from all over the world, national investment in artificial intelligence technology R \& D is rapidly increasing, and interest in various effects of AI on our society is also increasing. Relevant legislation on artificial intelligence-powered drones and autonomous vehicles is being promoted in each country (Rahman et al., 2019); (Rahman, 2019); (Rahman, 2017).

Therefore, the development of artificial intelligence creates a collingridge dilemma.

In other words, in the process of influencing or controlling technology development, there is a dilemma in which two opposing problems, information problem and power problem, which are closely connected to each other, are faced.

Such preventive technological risk management, in spite of scientific uncertainty, is recognized as a necessity when it is determined that a particular act is likely to cause serious, irreversible and widespread harm (Collingridge, 1980).

\section{Results and Discussion}

This study examined how the perception of new artificial intelligence technology affects policy governance through perception of risk.

Theoretical discussion on the risk of artificial intelligence and the research issues considering the impact on policy governance are as follows. 


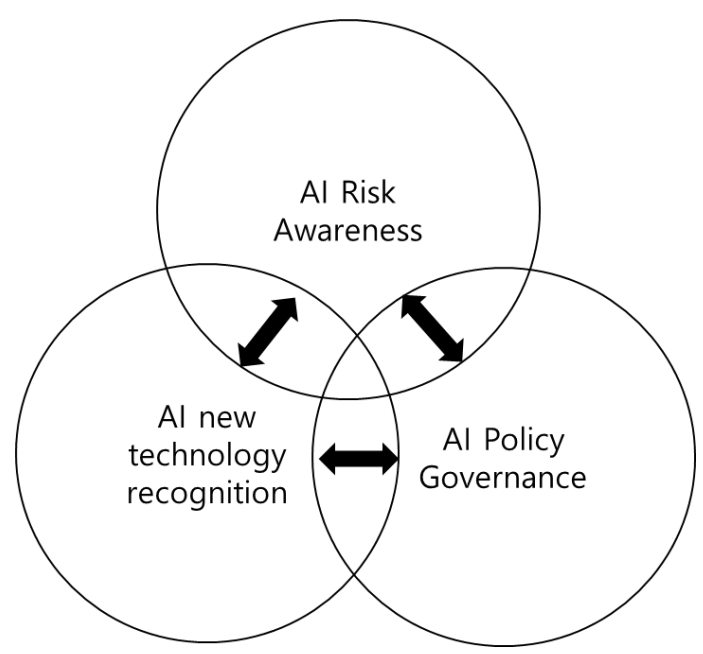

Figure 1. AI policy governance model

To determine the intent associated with the issue, each of the 21 items

Survey data were used to classify AI into new technology awareness, risk awareness, and policy governance.

Table 1. Questionnaire

\begin{tabular}{|c|c|c|}
\hline Domain & Q & Intentions \\
\hline \multirow{5}{*}{$\begin{array}{l}\text { Recognition } \\
\text { of new } \\
\text { technologies } \\
\text { related to } \\
\text { artificial } \\
\text { intelligence }\end{array}$} & Q1 & About the development of AI technology General \\
\hline & Q2 & AGI(Artificial General Intelligence) Development time \\
\hline & Q3 & AI Technology Benefits (Benefits) \\
\hline & Q4 & Benefits by sector due to the development of AI When to realize \\
\hline & Q5 & Commercialization level of AI technology by sector \\
\hline \multirow[t]{5}{*}{$\begin{array}{l}\text { Awareness of } \\
\text { the Dangers } \\
\text { of Artificial } \\
\text { Intelligence }\end{array}$} & Q6 & $\begin{array}{c}\text { • Probability } \\
\text { • Risk awareness } \\
\text { - Future generation impact } \\
\text { the risk to future generations) } \\
\text { • Scale and severity of risk } \\
\text { (seriousness) } \\
\text { • Dread of danger } \\
\text { • controllability of risk; } \\
\text { (controllability) } \\
\text { - Clarity of responsibility for risk } \\
\text { (accountability) } \\
\text { - Irreversibility of damage; } \\
\text { - Social risk status effect } \\
\text { - boomerang effect }[10] "\end{array}$ \\
\hline & Q7 & Risk occurrence and expression level by sector \\
\hline & Q8 & Infringement of social value by AI \\
\hline & Q9 & AI damage level according to AI \\
\hline & Q10 & Ethical Considerations for AI Technology \\
\hline
\end{tabular}




\begin{tabular}{|c|c|c|}
\hline \multirow{11}{*}{$\begin{array}{l}\text { Improved AI } \\
\text { Policy }\end{array}$} & Q11 & $\begin{array}{c}\text { Regulations on AI research and development } \\
\text { Necessity } \\
\text { Preregulation vs. Post Regulation } \\
\text { Sectoral Regulatory Needs } \\
\text { Specific Regulatory Activities }\end{array}$ \\
\hline & Q12 & Improvement of legal system \\
\hline & Q13 & $\begin{array}{l}\text { Areas requiring a proactive approach } \\
\text { Identification }\end{array}$ \\
\hline & Q14 & Supervisor of potential technical risk \\
\hline & Q15 & The primary responsible body for potential risks; \\
\hline & Q16 & Risk Assessment Agency \\
\hline & Q17 & $\begin{array}{l}\text { Priority due to labor market changes } \\
\text { Government policy }\end{array}$ \\
\hline & Q18 & Necessity of government regulation among future technologies \\
\hline & Q19 & $\begin{array}{c}\text { The Need for Government Policy for AI } \\
\text { Degree }\end{array}$ \\
\hline & Q20 & $\begin{array}{l}\text { AI among precautionary policy measures } \\
\text { Policy appropriate to risk }\end{array}$ \\
\hline & Q21 & $\begin{array}{l}\text { AI risks in resilience policy measures } \\
\text { Resilience Policy }\end{array}$ \\
\hline
\end{tabular}

\subsection{Recognition of New Technologies Related to Artificial Intelligence}

In the future, AI technology will be able to think and solve problems on its own, and will have the ability to evolve with free will. The respondents answered higher in the order of enhancing, convenience of life, and increasing in the order of increasing wealth, increasing social equity, and improving human fellowship.

It is expected that new artificial intelligence technology will be able to proactively cope with various industries based on the development of advanced big data and analysis technology in the near future, and through this, it will be possible to develop new industry and technology (Qi, 2019); (Rahman et al., 2018).

\subsection{Awareness of the Dangers of Artificial Intelligence}

The risk of artificial intelligence may be limited to the parties using it, but in the long term, there is a general opinion that it may occur universally to everyone. In the case of risks, 'intentional cyber attack, information manipulation, the economy, transportation, etc. were higher than other sectors. Especially, it was considered as the biggest recognition factor for AI risk in hacking and cyber attack.

\subsection{AI-Related Policy Improvements}

$84.2 \%$ of the need for regulation of risk and safety incidents related to AI research.

'It is necessary', and $70.0 \%$ of the respondents thought that 'pre-registration and post-regulation are necessary'. The field of medical care was the most needed field in which the precautionary principle was applied, and responded in order of crime policing, labor, and transportation.

The government responded with $48.4 \%$ of the most appropriate oversight agents for future new technology risks, including artificial intelligence.

In the case of potential risks and safety accidents of artificial intelligence, $41.6 \%$ of the respondents said that they were the first to be responsible for 'manufacturers', followed by 'government' (24.3\%), and so on.

\section{Conclusion}

Table 2 combines the three questions in the questionnaire: the benefits of Q3 AI technology, the infringement of social value by Q8 AI, and the necessity of government policy in preparation for Q19 - AI through four factors of artificial intelligence through factor analysis and correlation analysis. Through this, the infringement of value caused by AI (Beck, 1992) 
Freedom was high, according to the necessity of each policy against artificial intelligence risks.

And policies that enable early prediction and monitoring of future risks of AI.

Benefits are divided into technical and social benefits.

Table 2. Factor analysis

\begin{tabular}{|c|c|c|c|c|c|}
\hline & \multirow{2}{*}{ Risk factors of artificial intelligence } & \multicolumn{4}{|c|}{ factors } \\
\hline & & 1 & 2 & 3 & 4 \\
\hline \multirow{9}{*}{$\begin{array}{l}\text { With artificial } \\
\text { intelligence } \\
\text { Infringement } \\
\text { Degree }\end{array}$} & 4) verity & .759 & .124 & -.114 & -.012 \\
\hline & 2) Free & .752 & .019 & .033 & -.072 \\
\hline & 5) Human dignity & .730 & .124 & -.012 & -.078 \\
\hline & 8) Security & .716 & .186 & -.081 & -.024 \\
\hline & 6) Self-determination ability & .677 & .234 & .097 & -.202 \\
\hline & 1) safety & .646 & .080 & -.088 & .119 \\
\hline & 7) equal & .633 & .161 & .058 & -.257 \\
\hline & 3) health & .607 & -.104 & -.257 & .214 \\
\hline & 9) Privacy protection, including invasion of privacy & .566 & .246 & .198 & -.229 \\
\hline \multirow{6}{*}{$\begin{array}{l}\text { A.I } \\
\text { Prepared for } \\
\text { risk } \\
\text { Policy Needs }\end{array}$} & $\begin{array}{l}\text { 5) Information disclosure policy on AI risk for } \\
\text { citizens' right to know }\end{array}$ & .142 & .840 & .163 & -.023 \\
\hline & $\begin{array}{l}\text { 1) Policies to predict and monitor AI's future risks } \\
\text { early }\end{array}$ & .185 & .826 & .050 & .028 \\
\hline & 2) AI hedging policy & .143 & .815 & .002 & -.014 \\
\hline & 6) Resilience Enhancement Policy for AI Risks & .202 & .801 & .150 & .020 \\
\hline & $\begin{array}{l}\text { 4) Policy that citizens can participate in the } \\
\text { introduction of artificial intelligence risk assessment } \\
\text { system }\end{array}$ & .131 & .791 & -.038 & .072 \\
\hline & $\begin{array}{l}\text { 3) The policy that the beneficiary can bear the cost } \\
\text { of AI risk }\end{array}$ & .045 & .679 & .143 & -.077 \\
\hline \multirow{7}{*}{$\begin{array}{l}\text { Artificial } \\
\text { intelligence } \\
\text { Convenience } 1\end{array}$} & 2) automation of routine tasks & -.012 & .127 & .814 & -.084 \\
\hline & 1) Promoting Life Convenience & -.027 & .203 & .796 & .022 \\
\hline & 3) Productivity Improvement & .012 & .050 & .781 & .055 \\
\hline & 9) High level robot development & -.017 & .007 & .683 & -.010 \\
\hline & 10) Promoting health care & -.034 & .032 & .632 & .276 \\
\hline & 5) Improve resource utilization & -.071 & .014 & .625 & .387 \\
\hline & 11) extending human lifespan & -.031 & .107 & .568 & .359 \\
\hline \multirow{5}{*}{$\begin{array}{c}\text { Artificial } \\
\text { intelligence } \\
\text { Convenience } 2\end{array}$} & 7) Improve social equity & -.095 & -.036 & .001 & .787 \\
\hline & 8) Improve human fellowship & -.122 & .060 & -.054 & .745 \\
\hline & 12) eternal life of man & .067 & .013 & .113 & .648 \\
\hline & $\begin{array}{c}\text { 6) Reduction of adverse effects on the global } \\
\text { environment }\end{array}$ & -.131 & -.038 & .353 & .625 \\
\hline & 4) increase in wealth & -.056 & -.040 & .328 & .582 \\
\hline
\end{tabular}


This study examines the theoretical discussion on risk and how it affects policy governance. Cyber attacks in our society due to artificial intelligence technology. Information manipulation and other risks are emerging, and these risks have a need for regulation.

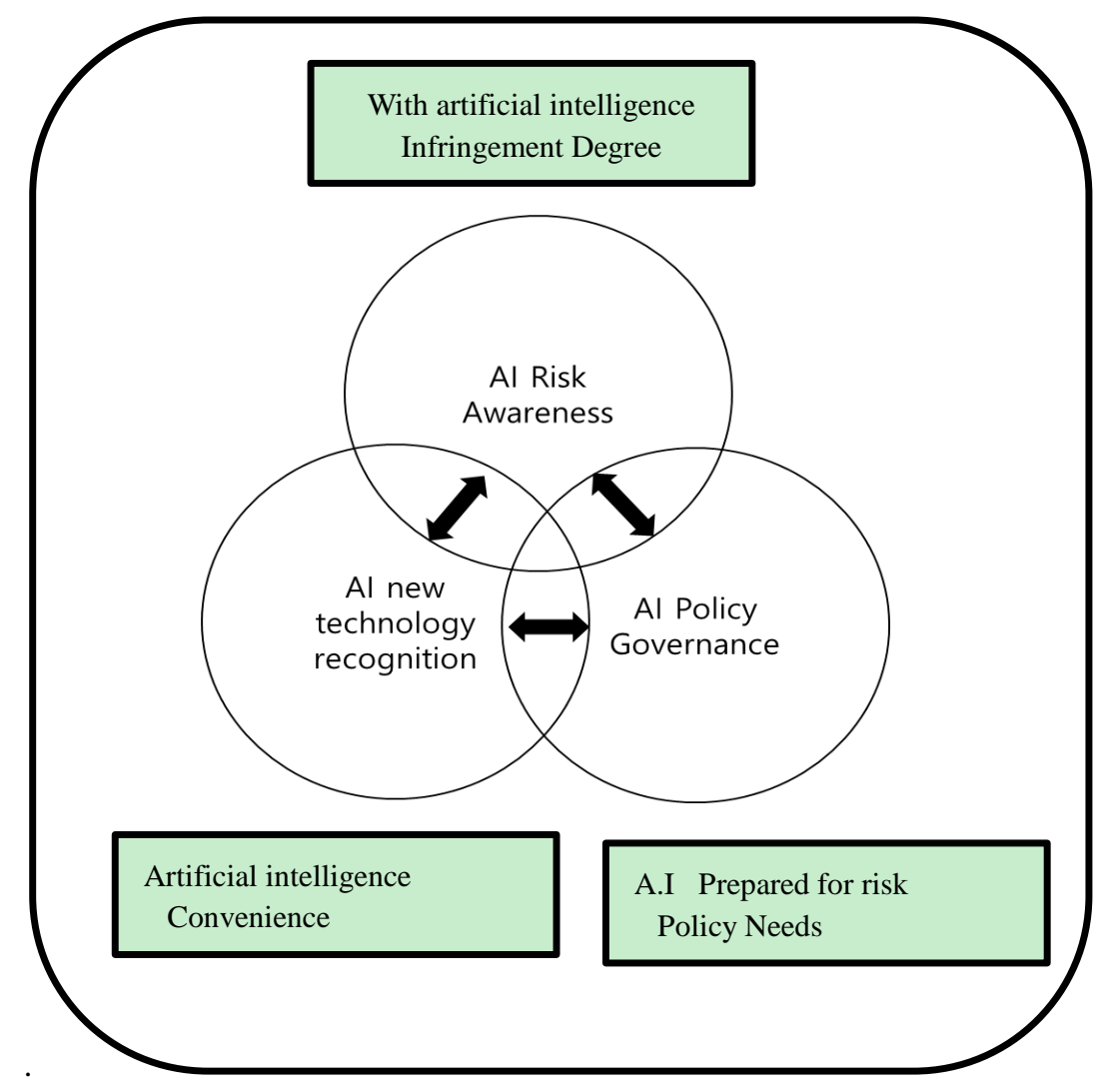

Figure 2. AI policy governance model

With the development of technology, new regulations, social norms, ethical discourses, regulatory and legal system improvements, risk management, etc. should be managed by the government as the supervisor, and the responsibility of accidents should be primarily the manufacturer and the government.

Further research is needed to analyze further how commercialization of AI technology recognition, benefits items and timing items affect policy governance through risk recognition.

\section{References}

Barrat, J. (2013). Our final invention: Artificial intelligence and the end of the human era. Macmillan.

Beck, U. (1992). Risk society: Towards a new modernity. New Delhi: Sage. The last job on Earth: imagining a fully automated world. Guardian Animations.

Bostrom, N. (2002). Existential risks. Journal of Evolution and Technology, 9(1), 1-31.

Carson, R. (2002). Silent spring. Houghton Mifflin Harcourt.

Collingridge, D. (1980). The dilemma of control. The Social Control of Technology, 13-22.

Effective Altruism Foundation. (2015). Artificial intelligence foundational research opportunities and risks, December 2015.

Frey, C. B., \& Osborne, M. A. (2013). The future of employment: How susceptible are jobs to computerisation?. Oxford Martin School Working Paper No. 7.

Hutzler, M. J., Sitzer, S., Holtberg, P. D., Conti, J., Kendell, J. M., \& Kydes, A. S. (2003). Annual Energy Outlook, 2004 Projection to 2025. United States Energy Information Administration, US Department of Energy, 
Washington, DC.

Paul Daugherty. (2017). 2017 Techonomy Magazine. Accenture Institute for High Performance.

Qi, H. (2019). A new literature review on financialization. Journal of Accounting, Business and Finance Research, 7(2), 40-50. https://doi.org/10.20448/2002.72.40.50

Rahman, M. M., Bindu, K. J., \& Islam, M. K. (2018). Linking per capita GDP to energy consumption, ecological footprint, and carbon dioxide emission in a developing economy in the world: The Case of Bangladesh.

Rahman, M. S., Rahman, M. A., \& Rahman, M. S. (2019). Prevalence and determinants of loneliness among older adults in Bangladesh. International Journal of Emerging Trends in Social Sciences, 5(2), 57-64. https://doi.org/10.20448/2001.52.57.64

Rahman, S. (2019). The nexus between urbanization, energy demand and healthcare in Bangladesh. Journal of Social Economics Research, 6(1), 13-19.

Rahman, W. A. W. A. (2017). Transformational leadership and empathy: The impact of quality in the health care services in Kelantan, Malaysia. International Journal of Economics, Business and Management Studies, 4(1), $50-56$. 